Hirohiko Hirano $\cdot$ Yoichi Ezura $\cdot$ Naoyoshi Ishiyama

Masatsune Yamaguchi · Ikuo Nasu · Hideo Yoshida

Takao Suzuki · Takayuki Hosoi · Mitsuru Emi

\title{
Association of natural tooth loss with genetic variation at the human matrix Gla protein locus in elderly women
}

Received: 27 January 2003/ Accepted: 11 March 2003/Published online: 29 April 2003

(C) The Japan Society of Human Genetics and Springer-Verlag 2003

\begin{abstract}
Natural tooth loss represents a major medical issue within the elderly population, since it impairs masticatory function critical for oral intake of essential nutrition. Contribution of genetic factors has been implicated in the determination of natural tooth loss; degree of reduction in number of natural teeth remaining intact (NTI) varies among individuals; thus, heterogeneity in NTI might reflect genetic variation within the population. One candidate gene, the matrix Gla protein gene (MGP), has been implicated in the pathogenesis of bone loss through a repression of bone/tooth formation. We have investigated a possible association between the CA repeat polymorphism at the human $M G P$ gene locus and the NTI in 458 elderly Japanese women. In 916 chromosomes tested, ten alleles of the polymorphic nucleotide repeat were observed (designated A1-A10), among which five alleles were regarded as major alleles to be tested for the association. Twentyseven women who possessed an A6 allele (164 bp) had significantly higher NTI than the remaining participants $(n=431)$, who did not carry an allele of that size (mean: 10.0 teeth vs 5.6 teeth; $P=0.007$, Mann-Whitney test).
\end{abstract}

H. Hirano $\cdot$ N. Ishiyama $\cdot$ M. Yamaguchi

Dentistry and Oral Surgery,

Tokyo Metropolitan Geriatric Medical Center, Tokyo, Japan

Y. Ezura · M. Emi $(\bowtie)$

Department of Molecular Biology,

Institute of Gerontology, Nippon Medical School,

1-396 Kosugi-cho, Nakahara-ku, Kawasaki 211-8533, Japan

E-mail: memi@nms.ac.jp

Tel.: + 81-44-7335230

Fax: + 81-44-7335192

I. Nasu

Department of Dental Public Health,

Nihon University School of Dentistry at Matsudo, Matsudo, Japan

H. Yoshida $\cdot$ T. Suzuki

Department of Epidemiology,

Tokyo Metropolitan Institute of Gerontology, Tokyo, Japan

T. Hosoi

Endocrinology Section,

Tokyo Metropolitan Geriatric Medical Center, Tokyo, Japan
An eight-year longitudinal follow-up study of NTI suggested that the genetic variations at the MGP locus did not affect the rate of tooth loss in the elderly period. These results suggest that genetic variation at the $M G P$ gene locus is associated with some determinants for tooth loss in elderly women.

Keywords Association study - Microsatellite marker . Tooth loss $\cdot$ Periodontal disease $\cdot$ Periodontitis · Matrix Gla protein

\section{Introduction}

Prevention of tooth loss is important for keeping masticatory function in elderly individuals (Hirano et al. 1999). A major cause of tooth loss in elderly people over 65 years of age resides in periodontal disease, equivalent to chronic periodontitis (Cahen et al. 1985; Reich et al. 1993; Morita et al. 1994; Hull et al. 1997; McCaul et al. 2001). Prevention of periodontal disease from an earlier stage of life is beneficial for maintenance of the masticatory function with sound natural teeth, thereby improving the quality of life (QOL) in the elderly population.

The use of quantitative trait markers as a surrogate disease index has been a rational approach in genetic studies for common polygenic diseases. Here we use the number of natural teeth remaining intact (NTI) in elderly individuals as an index of periodontal disease susceptibility. The concept is based on the consistency a number of previous studies have shown that the main cause of tooth loss in advanced age is chronic periodontitis (Cahen et al. 1985; Reich et al. 1993; Morita et al. 1994; Hull et al. 1997; McCaul et al. 2001). In the present study we focus on elderly population ( $>65$ years old).

The reduction in NTI in advanced age is not accompanied by any systemic qualitative abnormalities in mineral content or organic matrix. This indicates that 
existing chronic periodontitis, as well as the rate of local bone resorption, might influence the NTI, particularly in women after menopause, who tend to have rapid loss of bone mass. However, the degree of reduction varies among postmenopausal women; it follows that some of the genes in question are likely to act as regulators of bone resorption and periodontal inflammation. Heterogeneity in NTI might be a reflection of genetic variations within the population. Many endocrinological factors play roles in bone maturation and in the process of tooth loss that accompanies aging (Raizs 1988). In addition, since it is entirely possible that the pathophysiology or key genetic background of each patient is heterogeneous, a rational approach to understand the genetic background of periodontal disease/chronic periodontitis would require examination of the panel of genes in question.

One obvious candidate for such a study is $M G P$, the gene encoding the matrix Gla protein, which is a gammacarboxyglutamic acid-rich (Gla-rich), vitamin K-dependent apatite binding protein expressed in bone, cartilage and vascular smooth muscle (Yagami et al. 1999). It negatively controls calcium deposition in cartilage, arterial wall, and other soft tissues in general (Luo et al. 1997). The human MGP gene spans $3.9 \mathrm{~kb}$, consisting of four exons (Cancela et al. 1990), beside which we detected a CA-repeat polymorphism with 11 polymorphic alleles.

We hypothesized that genetic variations of the $M G P$ gene is one of the genetic determinants of bone metabolism and/or chronic periodontitis susceptibility, although it has not been clarified by now, partly because no useful genetic markers for this gene have been recognized so far. To test this hypothesis, we undertook to investigate correlation between NTI and genetic variation of the $M G P$ gene among elderly female population in Japan.

\section{Materials and methods}

Subjects

DNA samples were obtained from peripheral blood of 458 elderly Japanese women living in the rural area of northern Japan who participated in a dental examination including counting of number of natural teeth (Shinohara et al. 2001). Their ages ranged from 65 to 91 (mean, $72.2 \pm 5.81$ years). Among them, 172 women, aged from 65 to 85 years (mean, $70.3 \pm 4.58$ years at 1992), participated in a longitudinal survey of four dental examinations carried out every two years for a period of eight years. All were non-related volunteers and gave their informed consent prior to the study, which was approved by the Institutional Review Board of the Tokyo Metropolitan Institute of Gerontology. No participant had medical complications or was undergoing treatment for conditions known to affect bone metabolism, such as pituitary disease, hyperthyroidism, primary hyperparathyroidism, renal failure, adrenal disease or rheumatic diseases, and none was receiving estrogen replacement therapy.

\section{Measurement of the number of natural teeth}

The proposed index, NTI, in a subject person was estimated as an index of periodontal disease susceptibility in this study. Teeth were counted by routine dental examinations performed by seven experienced dentists, one of who participated in all five consecutive examinations. Examinations were performed in a well-calibrated manner, using a standard dental mirror and explorer under a fine artificial lighting. Before the examination, the dentists had calibration guidance in advance, where very loose teeth, non-masticating teeth, and teeth with only their stumps remained should be excluded from the count.

\section{Determination of microsatellite polymorphism by PCR}

PCR amplification of the CA repeat polymorphism at the $M G P$ locus was performed using primers: MGP-F, 5'-TAGTTAACTAGCTAAATTCCAA-3', and MGP-R, 5'-TTACTTACCTTCACGAATGAA- $3^{\prime}$. The examined CA repeat polymorphism (referenced sequence: 113793-113826 in AC007655 of the NCBI GenBank) localized at about $16 \mathrm{~kb}$ upstream from the transcriptional initiation site of the $M G P$ gene. The reaction volume of $10 \mu \mathrm{l}$ contained $20 \mathrm{ng}$ of genomic DNA obtained from peripheral blood, $10 \mathrm{mM}$ tris- $\mathrm{HCl}(\mathrm{pH} 8.4), 50 \mathrm{mM} \mathrm{KCl}, 1.5 \mathrm{mM}$ $\mathrm{MgCl}_{2}, 0.01 \%$ gelatin, $200 \mu \mathrm{M}$ dNTP, $2.5 \mathrm{pmol}$ of $\left[{ }^{32} \mathrm{P}\right]$-end-labeled MGP-R and of non-labeled MGP-F, and $0.25 \mathrm{U}$ Taq polymerase (Nakazawa et al. 2001). Cycle conditions were $94{ }^{\circ} \mathrm{C}$ for $4 \mathrm{~min}$, then 30 cycles of $94{ }^{\circ} \mathrm{C}$ for $30 \mathrm{~s}, 65^{\circ} \mathrm{C}$ for $30 \mathrm{~s}$, and $72{ }^{\circ} \mathrm{C}$ for $30 \mathrm{~s}$, with a final extension step of $5 \mathrm{~min}$ at $72^{\circ} \mathrm{C}$ in a Gene Amp PCR9600 System (Perkin Elmer Cetus, Norwalk, Conn., USA) (Harada et al. 2001). PCR products were electrophoresed for $2 \mathrm{~h}$ at $2,000 \mathrm{~V}$ in $0.3-\mathrm{mm}$ thick denaturing $6 \%$ polyacrylamide gels containing $36 \%$ formamide and $8 \mathrm{M}$ urea. Gels were transferred to filter papers, dried at $-80^{\circ} \mathrm{C}$, and autoradiographed. The size of each allele was determined by comparison with a sequencing ladder of control DNAs (Hattori et al. 2002).

\section{Statistical analysis}

The dominant effect of each allele of a given polymorphism was examined by comparing the NTI among individuals carrying the allele with those who did not, using non-parametric Mann-Whitney test. The recessive effect was examined similarly between homozygous carriers and the others, when it was possible. To test a codominant effect, analysis of variance (ANOVA) with regression analysis was performed using InStat 3.05 program (GraphPad software, San Diego, Calif.). Correlation or differences in means were considered statistically significant for $P$ values $<0.05$ (Ota et al. 2001). The association of the $M G P$ A6 allele with the agedependent change in the NTI was analyzed by Mann-Whitney test.

\section{Results}

Association of $M G P$ variation with NTI in the elderly population

The 458 postmenopausal Japanese women in our panel were genotyped for the CA repeat polymorphism at the $M G P$ locus. The polymorphic PCR products had been classified into ten alleles, A1 (172 bp, $22 \mathrm{CA}$ repeats) to A10 (154 bp, 13 CA repeats), by electrophoresis and autoradiogram. The distribution of the ten alleles in this population is shown in Fig. 1.

Correlating genotype(s) with NTI in the test population was sought in the five major alleles of the $M G P$ locus microsatellite marker, whose allelic frequency is greater than $3 \%$. The 27 women who possessed an A6 allele (164 bp, 18 repeats) showed significantly higher 
values of NTI than the women $(n=431)$ without this allele (mean $\pm \mathrm{SD}$ : $10.0 \pm 8.97$ vs $5.6 \pm 8.02(P=0.007$; Mann-Whitney test). Figure 2 shows the NTI-preserving effect of the A6 allele at the MGP locus. Background data of the groups with and without the A6 allele are summarized in Table 1 . We found no significant differences between the two groups with respect to mean age, height, or weight. Of the 27 women possessing the A6 allele, only one individual was homozygous at this locus; thus, examination for a co-dominant effect was eliminated.

Eight-year follow-up study of tooth loss and $M G P$ alleles

To test whether tooth loss rate per year in the elderly women is affected by the variation of $M G P$ gene, correlation was examined for eight-year tooth loss of the 172 subjects who had been followed up longitudinally for over eight years with examinations every two years. Rate of tooth loss was calculated in each individual by subtracting the NTI value obtained in previous measurement from the value measured in the given analysis. A consistent correlation between the specific SNP genotypes noted above and NTI was observed at every measured time point, reflecting the low NTI value among the A6 negative group at the initial point of the longitudinal study $(10.2 \pm 8.72$ vs $7.0 \pm 9.19)$. However,

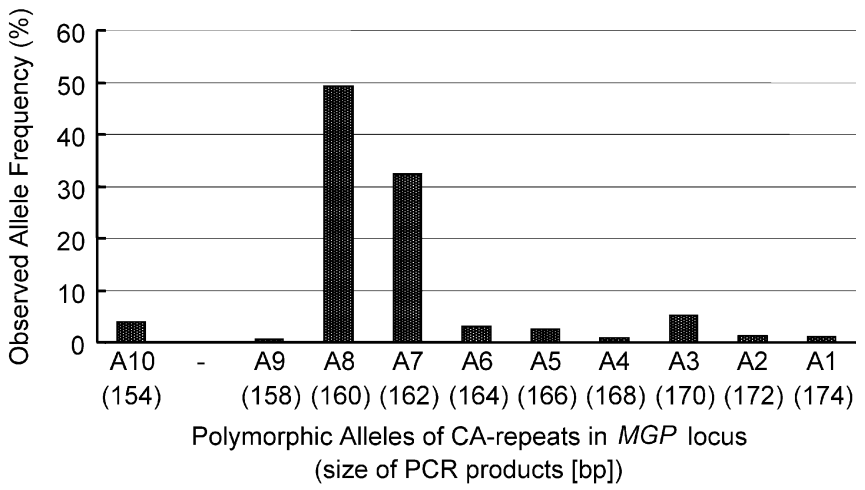

Fig. 1 Histogram representing the frequencies of 10 alleles identified for the CA repeat polymorphism in the MGP locus. Alleles are denoted downward from A1 (22 CA repeats) to A10 (13 CA repeats), according to their PCR product size from $154 \mathrm{bp}$ to $174 \mathrm{bp}$, respectively tooth loss rate per year in the elderly women is not correlated with the variation of $M G P$ gene (data not shown). It is worth noting that the 67 individuals of the 158 A6 negative subjects had already lost all their teeth $(\mathrm{NTI}=0)$ at the initial point, resulting in a low probability for further tooth loss during the period.

\section{Discussion}

In the work reported here we have shown an association of the CA-repeat variation in the $M G P$ gene locus with NTI in population of elderly Japanese women. Our data implied that the polymorphic variation of the $M G P$ gene might have affected bone metabolism or susceptibility for periodontitis in these women, eventually introducing a difference in NTI. Lowered NTI in postmenopausal women could be a result of accelerated tooth loss and/or structural weakness of the tooth and periodontal bone. A longitudinal follow-up study of NTI over eight years suggested that the genetic variations at the $M G P$ locus did not affect the rate of tooth loss in the elderly period.

It has been suggested that tooth loss/chronic periodontitis and osteoporosis/osteopenia may share some kind of genetic factors etiologically. For instance, clinically, Weyant and co-workers described enhanced loss of periodontal attachment in relation to osteopenia in older women (Weyant et al. 1999). Von Wowern and co-workers proposed osteoporosis as a risk factor of

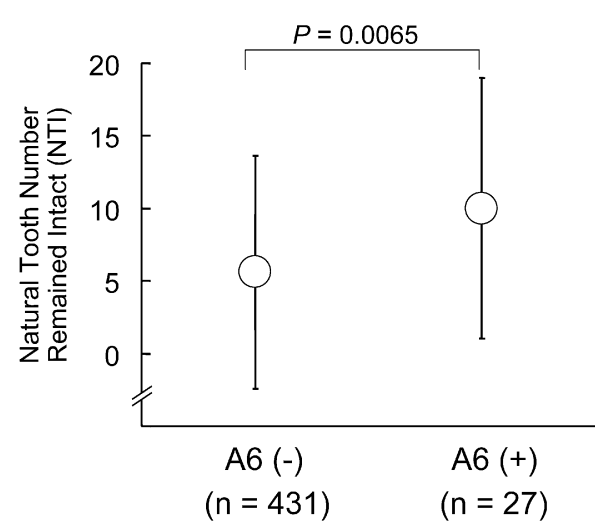

Fig. 2 Comparison of natural tooth number remained intact (NTI) between the subjects having the $M G P$ A6 allele [A6 $(+), n=27]$ and the subjects without A6 allele [A6 $(-), n=431] . P$ value was calculated for Mann-Whitney test $(P<0.05)$

Table 1 Basic characteristics of the study subjects

\begin{tabular}{lccc}
\hline & A6 $(-)(n=431)$ & A6 $(+)(n=27)$ & Statistical difference \\
\hline Age (years) & $72.3 \pm 588(65-91)$ & $70.0 \pm 405(65-79)$ & NS $^{\mathrm{b}}$ \\
Height $(\mathrm{cm})$ & $144.8 \pm 602(123.0-163.4)$ & $146.2 \pm 623(128.7-158.3)$ & $\mathrm{NS}^{\mathrm{a}}$ \\
Weight $(\mathrm{kg})$ & $49.6 \pm 852(31.4-80.7)$ & $49.2 \pm 650(38.9-64.5)$ & $\mathrm{NS}^{\mathrm{a}}$ \\
BMI $\left(\mathrm{kg} / \mathrm{m}^{2}\right)$ & $23.3 \pm 344(15.0-35.9)$ & $22.7 \pm 259(18.4-28.8)$ & NS $^{\mathrm{a}}$ \\
NTI & $5.6 \pm 802(0-29)$ & $10.0 \pm 897(0-27)$ & $P=0.0065^{\mathrm{b}}$ \\
\hline
\end{tabular}

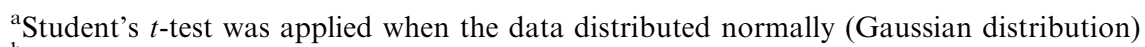

${ }^{\mathrm{b}}$ Mann-Whitney test was applied when the data did not distribute normally 
periodontal disease from clinical observation (von Wowern et al. 1994). Inagaki and co-workers linked variation of metacarpal bone density and tooth loss/chronic periodontitis (Inagaki et al. 2001). Although elucidation of mechanistic association awaits future study, these evidences support the involvement of shared genetic factors in tooth loss/chronic periodontitis and osteoporosis.

Others have described possible genetic risk factors influencing chronic periodontitis; for instance, IL-1 polymorphism was proposed as a risk factor for adult periodontal disease (Kornman et al. 1997; Engebretson et al. 1999; Amitage et al. 2000). Genetic analysis of tooth loss/chronic periodontitis in elderly population may not be straightforward, since the pathologic condition is etiologically confounded by influences of multiple environmental factors, such as smoking, aging, and oral hygiene habit (Hassell et al. 1995). For instance, in the present study, the unique dietary habit and nutrition condition in the rural area of northern Japan analyzed might have influenced on the phenotype of NTI. In this connection, it is intriguing to note the recent genetic finding of involvement of HLA, IL1, and Fc gamma locus (Engebretson et al. 1999; Ohyama et al. 1996; Kobayashi et al. 2001).

In this study, we showed a significant association of the CA-repeat variation localized at a $16-\mathrm{kb}$ distance in the $5^{\prime}$ flanking region of the $M G P$ gene with NTI of elderly Japanese women. One allele, A6 (164 bp, 18 CA repeats) was associated with higher NTI. The data presented here may suggest that variation/mutation in $M G P$ gene may affect genetic susceptibility for natural tooth loss/chronic periodontitis/bone metabolism and eventually cause variation in NTI. Since the MGP protein, a vitamin $\mathrm{K}$-dependent apatite binding protein, is known to be a negative regulator calcium deposition in bone, cartilage, and vascular smooth muscle tissues, and is important regulator for skeletal system development suggested by autosomal recessive disorder Keutel syndrome (Munroe et al. 1999). Genetic variation noted in the present study may exert its effect through subtle differences in its regulatory effects in maxillo-nasal bone structure or function, affecting oral soundness. Further genetic and functional study of the entire region of the $M G P$ gene and its control elements in affected individuals may shed light upon clarification. Of course, a possibility cannot be ruled out that the linkage disequilibrium with functional variants near the $M G P$ gene is responsible for the true mechanistic basis for the associations. Identification of true mechanistic variation(s) in addition to functional studies will be required to define these possibilities. Nevertheless, our data are in accord with the noted involvement of MGP protein in susceptibility to osteoporosis, another disease of bone mineral metabolism.

In summary, given our genetic results in elderly Japanese women, we suggest that the polymorphic microsatellite at the $M G P$ locus may become a useful marker for accelerated tooth loss/chronic periodontitis and to permit early therapeutic intervention in population at high risk for these conditions.
Acknowledgements We thank Mitsuko Kajita, Mina Kodaira, Miho Kawagoe, Kyoko Shimizu, Mayumi Tanaka, and Naoko Tsuruta for their technical assistance. This work was supported by a grant for Strategic Research from the Ministry of Education, Science, Sports and Culture of Japan; by a Research Grant for Research from the Ministry of Health and Welfare of Japan; by a Research for the Future Program Grant of The Japan Society for the Promotion of Science.

\section{References}

Armitage GC, Wu Y, Wang HY, Sorrell J, di Giovine FS, Duff GW (2000) Low prevalence of a periodontitis-associated interleukin-1 composite genotype in individuals of Chinese heritage. J Periodontol 71:164-171

Cahen PM, Frank RM, Turlot JC (1985) A survey of the reasons for dental extractions in France. J Dent Res 64:1087-1093

Cancela L, Hsieh CL, Franke U, Price PA (1990) Molecular structure, chromosomal assignment, and promoter organization of the human matrix Gla protein gene. J Biol Chem 265:15040-15048

Engebretson SP, Lamster IB, Herrera-Abreu M, Celenti RS, Timms JM, Chaudhary AG, di Giovine FS, Kornman KS (1999) The influence of interleukin gene polymorphism on expression of interleukin-1beta and tumor necrosis factor-alpha in periodontal tissue and gingival crevicular fluid. J Periodontol 70:567-573

Harada H, Nagai H, Tsuneizumi M, Mikami I, Sugano S, Emi M (2001) Identification of $D M C 1$, a novel gene in the TOC region on $17 \mathrm{q} 25.1$ that shows loss of expression in multiple human cancers. J Hum Genet 46:90-95

Hassell TM, Harris EL (1995) Genetic influences in caries and periodontal diseases. Crit Rev Oral Biol Med 6:319-342

Hattori $H$, Hirayama $T$, Nobe $Y$, Nagano M, Kujiraoka $T$, Egashira T, Ishii J, Tsuji M, Emi M (2002) Eight novel mutations and functional impairments of the LDL receptor in familial hypercholesterolemia in the north of Japan. J Hum Genet 47:80-87

Hirano H, Nasu I (1999) Masticatory ability in relation to oral status and general health on aging. J Nutr Health Aging 3:45-52

Hull PS, Worthington HV, Clerehugh V, Tsirba R, Davies RM, Clarkson JE (1997) The reasons for tooth extractions in adults and their validation. J Dent 25:233-237

Inagaki K, Kurosu Y, Kamiya T, Kondo F, Yoshinari N, Noguchi T, Krall EA, Garcia RI (2001) Low metacarpal bone density, tooth loss, and periodontal disease in Japanese women. J Dent Res 80:1818-1822

Kobayashi T, Yamamoto K, Sugita N, van der Pol WL, Yasuda K, Kaneko S, van de Winkel JG, Yoshie H (2001) The Fc gamma receptor genotype as a severity factor for chronic periodontitis in Japanese patients. J Periodontol 72:1324-1331

Kornman KS, Crane A, Wang HY, di Giovine FS, Newman MG, Pirk FW, Wilson TG Jr, Higginbottom FL, Duff GW (1997) The interleukin-1 genotype as a severity factor in adult periodontal disease. J Clin Periodontol 24:72-77

Luo G, Ducy P, McKee MD, Pinero GJ, Loyer E, Behringer RR, Karsenty G (1997) Spontaneous calcification of arteries and cartilage in mice lacking matrix GLA protein. Nature 386:78-81

McCaul LK, Jenkins WM, Kay EJ (2001) The reasons for extraction of permanent teeth in Scotland: a 15-year follow-up study. Br Dent J 190:658-662

Morita M, Kimura T, Kanegae M, Ishikawa A (1994) Watanabe Reasons for extraction of permanent teeth in Japan. T Community Dent Oral Epidemiol 22:303-306

Munroe PB, Olgunturk RO, Fryns JP, Van Maldergem L, Ziereisen F, Yuksel B, Gardiner RM, Chung E (1999) Mutation in the gene encoding the human matrix Gla protein cause Keutel syndrome. Nat Genet 21:142-144

Nakazawa I, Nakajima T, Harada $\mathrm{H}$, Ishigami T, Umemura $\mathrm{S}$, Emi M (2001) Human calcitonin receptor-like receptor for 
adrenomedullin: genomic structure, eight single-nucleotide polymorphisms, and haplotype analysis. J Hum Genet 46:132136

Ohyama H, Takashiba S, Oyaizu K, Nagai A, Naruse T, Inoko H, Kurihara H, Murayama Y (1996) HLA Class II genotypes associated with early-onset periodontitis: DQB1 molecule primarily confers susceptibility to the disease. J Periodontol 67:888-894

Ota N, Nakajima T, Nakazawa I, Suzuki T, Hosoi T, Orimo H, Inoue S, Shirai Y, Emi M (2001) A nucleotide variant in the promoter region of the interleukin-6 gene associated with decreased bone mineral density. J Hum Genet 46:267-272

Raizs LG (1988) Local and systemic factors in the pathogenesis of osteoporosis. N Engl J Med 318:818-828

Reich E, Hiller KA (1993) Reasons for tooth extraction in the western states of Germany. Community Dent Oral Epidemiol 21:379-383
Shinohara Y, Ezura Y, Iwasaki H, Nakazawa I, Ishida R, Kodaira M, Kajita M, Shiba T, Emi M (2001) Linkage disequilibrium and haplotype analysis among ten single-nucleotide polymorphisms of interleukin 11 identified by sequencing of the gene. J Hum Genet 46:494-497

von Wowern N, Klausen B, Kollerup G (1994) Osteoporosis: a risk factor in periodontal disease. J Periodontol 65:1134-1138

Weyant RJ, Pearlstein ME, Churak AP, Forrest K, Famili P, Cauley JA (1999) The association between osteopenia and periodontal attachment loss in older women. J Periodontol 70:982-991

Yagami K, Suh J-Y, Enomoto-Iwamoto M, Koyama E, Abrams WR, Shapiro IM, Pacifici M, Iwamoto M (1999) Matrix GLA protein is a developmental regulator of chondrocyte mineralization and, when consistently expressed, blocks endochondral and intramembranous ossification in the limb. J Cell Biol 147:1097-1108 